DOI: $10.26754 /$ ojs_aem/aem.2019304626

Aragón en la Edad Media

Recibido: $15 / 02 / 2020$

30 (2019) 371-387

Aceptado: 08/04/2020

e-ISSN: 2387-1377

ISSN: 0213-2486

\title{
EL PRIORATO DE SANTA CILIA DE PANZANO (HUESCA) EN EL SIGLO XII
}

\author{
THE PRIORY OF SANTA CILIA DE PANZANO (HUESCA) \\ IN THE $12^{\text {th }}$ CENTURY
}

\begin{abstract}
Resumen: El artículo se centra en la historia del priorato de Santa Cilia de Panzano de Huesca en el siglo XII. El patrimonio del priorato de Santa Cilia de Panzano estuvo localizado en las cuencas hidrográficas de los ríos Calcón y Formiga, en la zona controlada por el castillo musulmán de Labata, dentro del distrito musulmán de Huesca. El monasterio francés de Saint-Pons-de-Thomières fundó el priorato de Santa Cilia de Panzano entre 1099 y 1101. Las donaciones de Sancho Ramírez y de la nobleza oriunda de la zona fueron la base de sus posesiones. La explotación del dominio de Santa Cilia de Panzano es objeto de esta investigación que analiza las condiciones del uso de la tierra, los conflictos señoriales y las rentas feudales.
\end{abstract}

Roberto VIRUETE ERDOZÁIN

Departamento de Geografía e Historia

IES Leonardo de Chabacier (Calatayud) rviruetee@educa.aragon.es

\begin{abstract}
This paper focuses on the history of priory of Santa Cilia de Panzano de Huesca in the $12^{\text {th }}$ Century. The possessions of this priory were in the valleys of the rivers Calcón and Formiga in a muslim Labata castle area, a porcion of the ancient muslim area of Huesca. The French abbey Saint-Ponsde-Thomières founded the priory of the Santa Cilia de Panzano between 1099 and 1101. Her possessions mainly formed by donation of the king Sancho Ramirez and by native nobility. The economical exploitation of Santa Cilia de Panzano's priory is a main question of the paper. Thus, I analyse the terms of land use, and the conflicts between the priory and the peasants, and the feudal incomes.
\end{abstract}


Palabras clave: Santa Cilia de Panzano, rentas feudales, priorato, explotación del dominio, Hoya de Huesca, siglo XII.
Key words: Santa Cilia de Panzano, feudal incomes, priory, dominion exploitation, Hoya de Huesca, $12^{\text {th }}$ Century.

\section{Introducción}

Este trabajo sobre la documentación del priorato de Santa Cilia de Panzano se enmarca dentro de un proyecto cuyos principales fines radican en editar la documentación de San Pedro el Viejo de Huesca ${ }^{1}$ y estudiar su historia en los siglos X, XI y XII. ${ }^{2}$ Esta investigación se propone alcanzar tres objetivos muy definidos: profundizar en el conocimiento los primeros tiempos del reino de Aragón en la zona nororiental y oriental de la denominada Hoya de Huesca, ${ }^{3}$ ofrecer nuevas perspectivas en torno al priorato de San Pedro el Viejo ${ }^{4}$ y la integración de la población mozárabe en el Estado feudal aragonés, ${ }^{5}$ y aportar

1 La publicación de la documentación de San Pedro el Viejo de Huesca conservada en el Archivo Municipal de Huesca y en el Archivo Diocesano de Huesca está a punto de salir publicada en la colección Rememoranzas del Instituto de Estudios Altoaragoneses, que dirige María Dolores Barrios. La colección incluye también la documentación de San Úrbez de Serrablo entre los siglos X y XII y del priorato de Santa Cilia, que estudiamos en este artículo.

2 A fecha de hoy este proceso está en fase inicial. Varios avances han sido presentados en septiembre de 2017 con motivo de la conmemoración del noveno centenario de la construcción de San Pedro el Viejo de Huesca y del coloquio celebrado el Olorón (Francia) en diciembre de 2018 dedicado a la figura de Alfonso I de Aragón y de Pamplona. (Viruete, en prensa).

3 Silvia Arilla y José Ángel Asensio han puesto fin a una importante carencia de estudios sobre esta época en la zona de estudio. Ambos han procedido a estudiar la torre islámica de la ermita de La Magdalena de Panzano y el emplazamiento cristiano de Labatilla y abordan la época musulmana y los primeros años del territorio bajo control del reino de Aragón tras la conquista de estas tierras a los musulmanes. (Arilla-Asensio, 2017: 65-94).

4 Sólo contamos con los estudios sobre San Úrbez de Serrablo realizados por Ángel Canellas y Carlos Laliena. Este último autor hace algunas alusiones a la época del priorato, pero se centra principalmente en el estudio del monasterio antes de ser donado por Sancho Ramírez a Saint-Pons-de-Thomières. (Canellas, 1943: 3-34; Laliena, 1999a: 831-846).

5 El tema de los mozárabes en la ciudad de Huesca fue abordado de manera muy aislada por Federico Balaguer a mediado de los años cuarenta del siglo XX. Por otro lado, Lacarra estudió la campaña de Alfonso I de Aragón en Andalucía en la que trajo a un grupo de mozárabes. (Balaguer, 1946a: 397-416; Balaguer, 1946b; Lacarra, 1977). Después, a finales del siglo Xx y hasta la actualidad, Philippe Sénac, Roberto Viruete y Guillermo Tomás han hecho referencia muy general a la cuestión aludiendo a la emigración de mozárabes de la taifa de Zaragoza al reino de Aragón en la primera época de Ramiro I de Aragón. (Sénac, 2000: 333-336; Viruete, 2008: 640-641; Tomás, 2016). Recientemente un estudio de María Luz Rodrigo Estevan y María del Mar Agudo Romeo presentado en el marco de la Troisième Transpyrenalia (Oloron-Sainte Marie, déc., 2018) también ha abordado la cuestión de los mozárabes traídos por Alfonso I. 
un nuevo estudio sobre las instituciones eclesiásticas de la zona ${ }^{6}$ y el rol de los clérigos franceses en ellas. ${ }^{7}$ Sin embargo, con este artículo solo aspiro a iniciar la larga tarea necesaria para alcanzar los objetivos del proyecto. Sus resultados han de tomarse como ideas introductorias al estudio de San Pedro el Viejo de Huesca. Por último, la jubilación del profesor Juan Fernando Utrilla Utrilla, quien no sólo ha desempeñado una parte fundamental de su actividad docente en Huesca, sino que ha dedicado también muchas investigaciones a este territorio, me han impulsado a redactar el presente artículo relacionado con la comarca de Huesca.

\section{El priorato de Santa Cilia de Panzano: precedentes, conquista aragonesa y creación del priorato}

El dominio del priorato de Santa Cilia se ubica en el somontano que separa el norte de la depresión del Ebro y las sierras exteriores del Pirineo. En efecto, encontramos sus tierras al pie de la imponente Sierra de Guara, entre los cerros y barrancos que confluyen en los complejos valles de los ríos Formiga y Calcón. Estos ríos pertenecen a la parte occidental de la cuenca hidrográfica

6 Las instituciones eclesiásticas con dominio en Huesca en el siglo XII que han sido objeto de estudio son: el propio San Pedro el Viejo, analizado por Federico Balaguer, el monasterio de Montearagón, por Ricardo Del Arco, el monasterio de San Victorián, por Ángel Juan Martín Duque, la catedral de Huesca por Juan Utrilla y la encomienda del Temple por Antonio Gargallo, María Teresa Iranzo, María José Sánchez y Ánchel Conte. (Balaguer, 1946b; Del Arco, 1963: 1-50; Martín, 1957: 93-109; Utrilla, 1984: 19-46; Gargallo y otros, 1981: 7-56; y Conte, 2010: 285-318).

7 El estudio de los franceses en la Península Ibérica durante los siglos XI y XII es uno de los temas clásicos de la historiografía en los estudios sobre Aragón desde que el hispanista francés Deforneaux y José María Lacarra publicaran los primeros estudios a mediados del siglo XX. (Deforneaux, 1949; Lacarra, 1968b: 65-80; Laliena, 2000: 149-169; Giunta, 2017). No obstante, en el caso de San Pedro el Viejo de Huesca se ha estudiado de modo muy completo - también desde mediados de los años cuarenta del siglo pasado - , la función desempeñada por el abad del monasterio de Saint-Pons-de-Thomières, Frotardo, como legado pontificio del papa Gregorio VII en el proceso de reforma eclesiástica que hizo Sancho Ramírez en el reino de Aragón y en la formación eclesiástica del futuro Ramiro II. Los estudios son muy numerosos destacando, entre otros, los de Kehr (1945: 285-326; y 1946: 74-185), Durán (1962), Buesa (1978 y 1996), Laliena, (1996) y Giunta (2017). Sin embargo, apenas se ha abordado la labor como rector de las propiedades que su monasterio recibió en Huesca y cómo influyó la gestión de los monjes franceses en la evolución del priorato y en sus manifestaciones artísticas. También Giunta (2012: 123-142) ha estudiado la fundación del priorato de Santiago de Ruesta por el monasterio de La Sauve-Majeure, situado en las cercanías de Burdeos. En los últimos años, desde el Departamento de Arte de la Universidad Complutense y bajo la dirección de Javier Martínez de Aguirre se viene desarrollando un proyecto de investigación titulado Arte, ideología y poder en Aragón en el siglo XI que está contribuyendo a solventar este vacío. La última publicación relevante del proyecto, que investiga también la figura de Frotardo, es el análisis de las portadas de la catedral de Jaca. (García, 2018). 
del río Alcanadre, que pone fin a la comarca de la Hoya de Huesca en su parte este. A pesar de su revirada y ondulada geografía, esta zona nunca ha permanecido vacía de grupos humanos. El hombre ya se instaló aquí en el Paleolítico Superior en la cueva de Chaves. ${ }^{8}$

En época musulmana, el estudio de Silvia Arilla y José Ángel Asensio es el primero que nos ofrece datos sobre la ocupación de la mayor parte del territorio que abarcaba el dominio del priorato de Santa Cilia. Al margen de centrarse en el análisis de la ermita de La Magdalena y del castillo de Labatilla, sede de un distrito castral cristiano, ambos arqueólogos constatan que los aragoneses mantuvieron tras la conquista los mismos núcleos de habitación existentes desde la época califal, limitándose los cambios operados por el reino de Aragón en la fragmentación y reducción del territorio dependiente de los husun musulmanes. Así, de la superficie vinculada al hisn de Labata, al que pertenecerían los valles del Calcón y del Formiga, aparecería más de un distrito castral, como el de Labata, infeudado a uno de los nobles aragoneses, o el de Labatilla. ${ }^{9}$

¿Cuándo se conquistó este territorio por el reino de Aragón? El territorio del Calcón y Formiga debió ser conquistado entre los años 1087, cuando se construye Montearagón y 1093. Aunque también podría ceñirse la ocupación al bienio 1092-1093, tras la toma de Labata y antes de que Sancho Ramírez donase a Saint-Pons-de-Thomières el 7 de mayo de 1094 estas tierras. En esta fecha, el monarca concedió a dicha abadía, entre otros muchos bienes, el mo-

Para las referencias bibliográficas, remito a la publicación divulgativa del libro Comarca de La Hoya de Huesca editado por el Gobierno de Aragón dentro de la Colección Territorium, en lo relativo a las cuestiones geográficas y prehistóricas. (Cuchi, 2006a: 21-26; Cuchi, 2006b: 27-32; Castán, 2006: 33 56; y Baldellou, 2006: 59-74).

9 Arilla-Asensio, 2017: 65-94. La organización del distrito musulmán de Huesca ya la estudió entre los años ochenta y noventa del siglo pasado Philippe Sénac, cuya tesis doctoral publicada en el año 2000 citamos en este trabajo. El territorio rural se articuló en una serie de castillos con presencia de guarnición militar: los husun. A su vez, dentro de las tierras que estas fortalezas controlaron existieron una serie de asentamientos como hábitats fortificados, núcleos fortificados sin vinculación a hábitat (algunos no siempre estuvieron ocupados), y almunias, esto es, explotaciones rurales propiedad de las elites urbanas utilizadas a modo de fincas de ocio y descanso. Sin embargo, en la obra de Sénac no aparece ninguna población relacionada con el dominio del priorato de Santa Cilia, excepto el hisn de Labata al que corresponden. (Sénac, 2000: 187-268). En este sentido, el trabajo de Arilla y Asensio dan detalle de las poblaciones existentes en la cuenca occidental del río Alcanadre. Asimismo, constatan que el yacimiento de la fortaleza musulmana sobre la que se construyó la ermita de La Magadalena en Panzano hay que entenderla como una de estas fortificaciones no asociadas a hábitat que ya estableció Sénac. Por otro lado, estos autores evidencian con detalle la fragmentación del territorio castral musulmán y el surgimiento de distritos castrales más pequeños. En suma, las investigaciones de Arilla y Asensio permite conocer una parte del territorio del hisn de Labata y los cambios producidos por la conquista aragonesa. 
nasterio de San Úrbez, el distrito castral de Labatilla con su iglesia y sus lugares dependientes - Morrano, Yaso, Bastarás y Panzano- y la iglesia de Santa Cilia con la mitad de su término. ${ }^{10}$

¿Cuándo se creó el priorato? Antes de que fuera creado, el obispo de Huesca-Jaca, con el visto bueno del rey Pedro I, modificó, tras la conquista de Huesca, el reparto de los centros religiosos que su padre Sancho Ramírez había hecho: la capilla de la Zuda para Saint-Pons-de-Thomières y la mezquita principal para Montearagón. El obispo logró su objetivo, de modo que finalmente el 16 de diciembre de 1096 la capilla de la Zuda fue para Montearagón y Saint-Pons-de-Thomières obtuvo la iglesia mozárabe de San Pedro el Viejo de Huesca. ${ }^{11}$ El abad Frotardo convirtió esta iglesia en un priorato que fue el núcleo rector de todas las posesiones obtenidas por Saint-Pons-de-Thomières antes y después de la conquista de Huesca. Ya a finales de abril de 1097 se documenta la primera donación de un particular, Pedro de Almaria, al priorato de San Pedro el Viejo. ${ }^{12}$ Esta cesión precedió a la donación de casas, tiendas y animales que hizo el 9 de mayo el rey Pedro I. ${ }^{13}$ Sin embargo, el primer prior, Berenguer, no nos ha quedado documentado antes de abril de 1099. ${ }^{14}$

La creación de los prioratos de San Úrbez de Serrablo y de Santa Cilia no tardó mucho más. A título de hipótesis creo que debió tener lugar entre 1099 y 1101. Ya en 1102, Berenguer, ejerciendo también como prior de ambos centros dependientes de San Pedro, compró al senior Orti Ortiz la mitad del término de Santa Cilia de Panzano por cuatrocientos sueldos. ${ }^{15}$

10 Viruete, 2020: $\mathrm{n}^{\mathrm{o}} 20$.

11 Viruete, 2020: $n^{\circ}$ 22: «Anno incarnationis domini nostri Ihesu Christi millessimo nonagessimo sexto. Deuicto rege cesaraugustano / et occisa multa gente paganorum et etiam christianorum ad ad uictoria ferentium, circiter XXX $X^{\mathrm{a}}$ milia, V kalendas de- / cembris ingressus est inuictissimus rex Petrus in Osca ciuitatem, quo intrante capellaniam zude dedit / abbati Sancti Poncii, sicut pater eius donauerat. Sig unquam abeo capta fuisset, quam in capellaniam eam teneret abbas / Sancti Poncii a die illa usque ad sextum decimum diem kalendas ianuarii, et episcopo iaccensis queieret miskidam ut sedem episcopalem / in ea poneret, et rex cum abbate Simone contradicerent eoquod Sancius rex dederat illam Ihesu Nazareno de Montearagone. Pre- / sente archiepiscopo terragonensi et episcopo pampilonensi et Didaco episcopo Sancti Iacobi, facta est de hac re talis conmutatio ut / episcopus iaccensis haberet miskidam pro sede cum omnibus suis pertinenciis, et abbas Sancti Poncii et monachi eius haberent illam / ecclesiam antiquam Sancti Petri cum omnibus ad se pertinentibus, et ecclesiam Ihesu Nazareni haberet capellaniam de zuda cum omni iure / suo quod factum est.»

12 Viruete, 2020: $n^{\circ} 24$.

13 Viruete, 2020: $n^{\circ} 26$. El día de antes, Frotardo dispuso que que las rentas de las posesiones oscenses de Saint-Pons-de-Thomières, excepto San Pedro, se destinaran para el vestido de sus monjes. (Viruete, 2020: $\left.n^{\circ} 25\right)$.

14 Viruete, 2020: $n^{\circ} 29$.

15 Viruete, 2020: $\mathrm{n}^{\mathrm{o}} 38$. 


\section{La construcción de la iglesia de Santa Cilia de Panzano y la formación del dominio del priorato}

Saber la cronología de la iglesia de Santa Cilia de Panzano resulta complicado a día de hoy. Una vez que San Pedro pasó a ser una entidad dependiente del concejo de Huesca en 1535, la iglesia se reconstruyó por completo en el siglo XVIII, aspecto que tiene en la actualidad siguiendo la descripción y análisis de Silvia Arilla. ${ }^{16}$ En la fábrica conservada hasta hoy se usaron algunos de los capiteles románicos de la iglesia original. La documentación archivística señala que su iglesia se construyó con posterioridad a la de San Úrbez de Serrablo, que estaba rehaciéndose entre 1135 y $1137 .{ }^{17}$ Dos mujeres, Cornelia y Toda, donaron bienes en Casbas y en Blecua respectivamente en 1143 para la construcción de la iglesia de Santa Cilia. ${ }^{18}$ Por lo tanto, es plausible fechar el proceso de construcción a mediados del siglo XII. Sería interesante contrastar la información archivística con el estudio de los capiteles, pues ello podría arrojar una cronología similar o dentro del propio siglo XII.

$\mathrm{Al}$ igual que todas las instituciones religiosas, el patrimonio que adquirió Santa Cilia de Panzano procedió de tres vías: donación de terceros, compraventa y permuta. La primera de ellas parece que fue, como resultó común para otros centros de la época, el procedimiento principal para la formación del patrimonio. Así lo confirman once de los catorce documentos analizados, en los que se atestigua entrada de propiedades a favor de Santa Cilia de Panzano. Acerca de los otros dos métodos, tan solo han quedado registradas en la documentación disponible tres compras y ninguna permuta. ${ }^{19}$

Un análisis de la cronología del dominio del priorato de Santa Cilia permite constatar que la formación del priorato debió ser posterior al momento en que Saint-Pons-de-Thomières recibió el grueso de las propiedades nucleares de Santa Cilia de Panzano, integrado por las propiedades reales del castrum de Labatilla e incluyendo este lugar además de los de Morrano, Yaso, Bastarás y Panzano, y la mitad de Santa Cilia de Panzano, junto con sus iglesias. Al final

16 Véase la siguiente dirección web de Sistema de Información y Patrimonio Cultural de Aragón: http:// www.sipca.es/censo/1-INM-HUE-006-081-060/Iglesia/de/Santa/Cecilia.html\#.XxoA8p4zbIU

17 Viruete, 2020: $\mathrm{n}^{\circ}$ 97, 98 y 99.

18 Viruete, 2020: $\mathrm{n}^{\circ} 105$.

19 Si atendemos al tenor documental, podríamos añadir una compra y una permuta más. Pero si leemos con detenimiento su contenido, parece que se tratan de documentos expedidos en relación con la explotación del patrimonio por parte del priorato de Santa Cilia. (Viruete, 2020: nº 200 y 262). 
del reinado de Pedro I, se completó este territorio fundacional con la compra de la otra mitad de Santa Cilia de Panzano. A partir de aquí, el patrimonio inmueble se fue ampliando hasta 1180 de forma puntual, tanto en el espacio - principalmente en Panzano-, como en el tiempo. Los periodos de adquisición se concentran al inicio y al final del reinado de Alfonso I (1104-1134), pero también en 1143 y en los primeros quince años del reinado de Alfonso II $(1162-1196){ }^{20}$

Respecto a las personas que contribuyeron a formar el patrimonio del priorato de Santa Cilia, la práctica totalidad de los donantes pertenecían a la nobleza, además del obispo de Huesca-Jaca y la casa real. En lo que a la nobleza se refiere, cabe destacar al senior García Garcés o García Arceíz, que donó una parte de sus bienes a Santa Cilia de Panzano en su testamento de 1134, y a su mujer, que confirmó esos bienes entre 1134 y 1164. Las mujeres aparecen como agentes importantes en la gestación del dominio de este priorato: se han conservado las donaciones de Cornelia, hija del senior Sancho Garcés, y las de su esposa Toda, ${ }^{21}$ y también las cesiones que hizo Sancha, hija de García Sanz $^{22}$ y Toda, mujer de Jimeno Garcés. ${ }^{23}$

¿Dónde se ubica geográficamente el patrimonio inmueble de Santa Cilia de Panzano? El dominio es compacto y está concentrado en el noreste de la actual comarca de La Hoya de Huesca, en el somontano al sur de Sierra de Guara. No hemos contabilizado unas heredades en Labata y en Zaragoza, cuya propiedad no está totalmente clara. El grueso patrimonial lo hallamos en Santa Cilia de Panzano, propiedad completa del priorato desde 1102, y en Panzano, lugar en el que la iglesia poseyó alrededor de una quincena de bienes entre el palacio, casas, heredades, campos, viñas y un corral. Además, tuvo posesiones en Morrano, Bastarás, Yaso, Labatilla - emplazamiento de poblamiento fallido-, y Casbas. Todo ello se ubica entre el río Alcanadre, más cerca de Morrano, y el Barranco de las Hoyas entre los ríos Guatizalema y Calcón; concretamente en las cuencas hidrográficas del río Formiga (Santa Cilia de Panzano) y del Calcón (Panzano). Fuera de este núcleo, Santa Cilia tuvo pro-

20 Viruete, 2020: $n^{\circ}$ 61, 72, 90, 104, 105, 177, 210 y 212. Además, existe el patrimonio de García Arceíz que mantuvo su esposa en vida y que desconocemos cuándo entró a formar parte de los bienes de Santa Cilia, y la propiedad en Coscullano, cuyo dominio conocemos por una cesión a terceros. (ibidem, $\mathrm{n}^{\circ}$ 93, 160 y 220$)$.

21 Viruete, 2020: no 104.

22 Viruete, 2020: no 212.

23 Viruete, 2020: nº 105. 
piedades inmuebles en Coscullano (en la cabecera del río Rija) y en Blecua, sito en el tramo final del mismo curso fluvial, que en el mapa aparece como Barranco de las Hormigas y que desemboca en el Alcanadre.

Para cerrar la parte del patrimonio del priorato de Santa Cilia, aludiremos brevemente al patrimonio mueble que dejaron en sus testamentos el senior García Arceiz y su esposa María, la cual, años después, confirmó lo dispuesto por su marido. Además de ganado — caballo, yeguas, ovejas y cerdos-, destaca un lecto, un tapete de buena calidad, un plumaz, dos lunas, un apezab, un fatel y un alamar ${ }^{24}$ Este matrimonio es, sin duda, el principal linaje ligado al priorato, ya que García Arceiz se hizo monje y su esposa eligió como lugar de enterramiento la iglesia de Santa Cilia. ${ }^{25}$

\section{Explotación económica del dominio}

A partir de la segunda mitad del siglo XII tenemos una mayor información sobre la explotación económica del dominio, lo que no quiere decir que no se dispongan de datos con anterioridad a dicha fecha. En efecto, la explotación económica del dominio debió comenzar al poco tiempo de ir acumulando propiedades, especialmente en lo referente a los derechos eclesiásticos, disponibles ya desde las primeras donaciones recibidas.

Los primeros ingresos del priorato fueron, sin duda, los diezmos, primicias, oblaciones y los derechos episcopales - excepto el sinodial-, de las iglesias de Santa Cilia, Morrano, Yaso y Bastarás. Sin embargo, aunque es citada la iglesia de Labatilla, no hay mención documental ninguna más allá de los documentos de donación de Sancho Ramírez y del obispo de Huesca-Jaca. Hemos de deducir que se produjo un poblamiento fallido, como ya se ha comentado, que han refrendado las investigaciones arqueológicas de Silvia Arilla y José Ángel Asensio.

Al margen de las rentas eclesiásticas, la explotación económica del patrimonio se encuadra dentro de una sociedad feudal y señorial caracterizada por la diversidad de rango y status entre las personas dependientes. Así, se observa una gran heterogeneidad a escala local tanto entre los distintos señores feudales como entre los propios habitantes de distintos lugares propiedad de un 


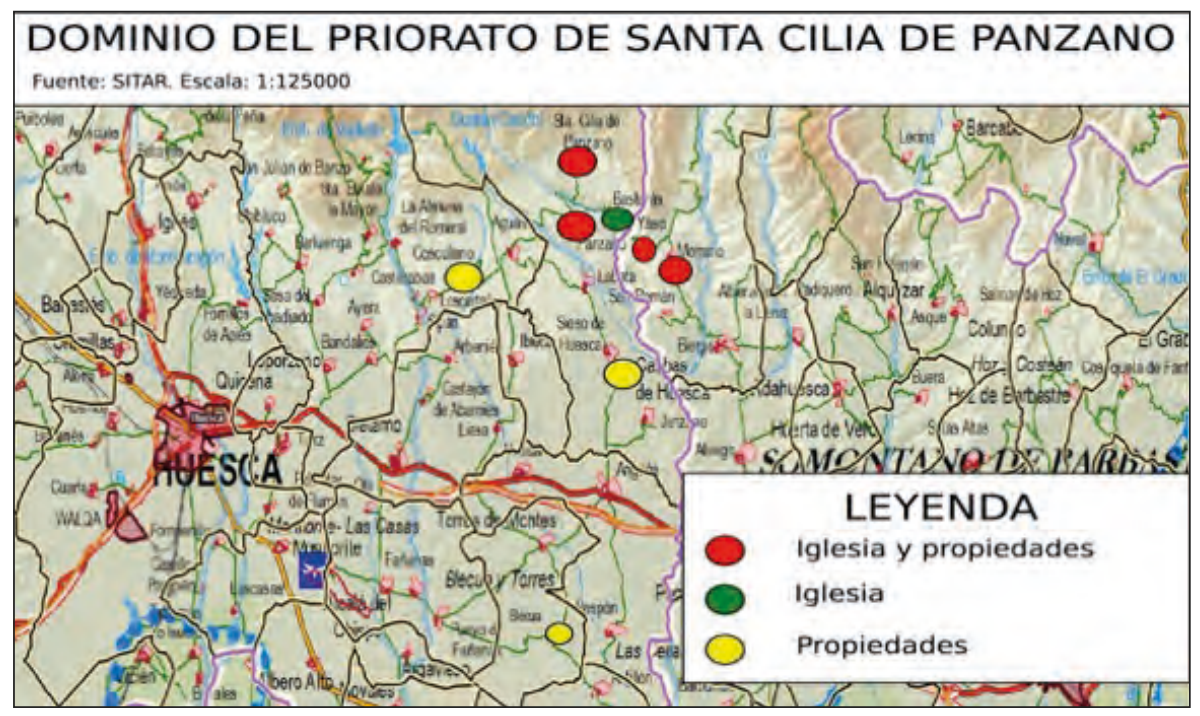

Fuente: Elaboración propia a partir del SIG-PAC del FEGA.

mismo señor. No obstante, sólo nos es posible estudiar de forma más específica las rentas señoriales en Panzano, Morrano, Blecua y Coscullano. ${ }^{26}$ En el resto de lugares por donde Santa Cilia extendió su dominio no hemos localizado datos correspondientes al siglo XII.

En las propiedades que Santa Cilia de Panzano tenía en Morrano, Blecua y Coscullano, la casa filial de Saint-Pons-de-Thomières y San Pedro el Viejo de Huesca, exigió a sus campesinos dependientes la novena de todos los frutos obtenidos de la tierra y la novena de carne en Morrano y Coscullano, ${ }^{27}$ mientras que en Blecua demandó la novena de pan y de vino. ${ }^{28}$ Además, en la localidad de Morrano, en la que también San Pedro el Viejo tenía propiedades, ambos priores acordaron hacia finales del siglo XII e inicios del XIII repartirse la novena en aquellas tierras que las personas dependientes de ambos prioratos compraran, empeñaran o trabajaran de manera conjunta. ${ }^{29}$

26 Viruete, 2020: $\mathrm{n}^{\mathrm{o}} 121,145,165,186,206,217,220,262,313$ у 353.

27 Viruete, 2020: $\mathrm{n}^{\circ} 186$ y 220.

28 Viruete, 2020: $\mathrm{n}^{\circ} 121$.

29 Viruete, 2020: $n^{\circ} 353$. 
En Panzano, el panorama es radicalmente distinto y muy variado. Ninguna de las personas vinculadas a Santa Cilia de Panzano satisfizo novena en las seis operaciones relacionadas con la explotación del dominio del priorato en este lugar. ${ }^{30}$ Por la cesión de casal o de casas en el palacio del priorato, se estipuló el pago de doce monedas en $1161^{31}$ y de doce dineros en $1178 .{ }^{32}$ Sin embargo, en 1166 por conceder la explotación de casas junto al palacio y una viña, los usufructuarios tuvieron que satisfacer seis cuartales de ordio, media medida de vino, medio carnero y cuatro panes. ${ }^{33}$ Se ha observado que en varios casos, los bienes cedidos en explotación fueron los mismos pero el tributo exigido difirió en cada ocasión. Así, Fortún de Navardún y su esposa Gason tributaron por completo en especie por unas casas mientras que Domingo Picador y su familia lo hicieron en dinero por esas mismas casas. En 1177, Pedro de Yaso solo debía entregar un carnero por explotar los tres campos y una viña que le había cedido el priorato, ${ }^{34}$ siendo uno de esos campos el entregado a Santa Cilia de Panzano por García el 31 de julio de 1169..$^{35}$ En 1189, con motivo de la venta de una viña destinada a la honor de la iglesia de San Pedro de Panzano, el documento establece que los vecinos de Panzano pagasen de manera individual doce dineros a Santa Cilia. ${ }^{36}$ Por último, a finales del siglo, el primero de abril de 1196, el prior de Santa Cilia condonó a Poncio y sus hermanos el tributo de dos cahíces en trigo y ordio por valor de sesenta y ocho sueldos que eran pagados al priorato por la faja de viña que cultivaba su familia, primero su padre y después ellos; a cambio, les asignó un nuevo tributo anual por la misma propiedad a pagar en agosto, consistente en dos arrobas entre trigo y ordio. ${ }^{37}$ La nueva tributación parece que supuso una clara mejora para los campesinos si nos atenemos a las estimaciones de pesos y medidas vigentes en Aragón, pues un cahíz de áridos equivalía a cuatro arrobas. ${ }^{38}$

En suma, censos en metálico o en especie en Panzano, pero nunca novena como en Morrano, en Blecua o en Coscullano. Otro hecho reseñable es que en el priorato de Santa Cilia se pidió un nuevo tributo por conceder en feudo sus

30 Viruete, 2020: $\mathrm{n}^{\mathrm{o}} 145,165,206,217,262$ у 313.

31 Viruete, 2020: $\mathrm{n}^{\circ} 145$.

32 Viruete, 2020: $\mathrm{n}^{\circ} 217$.

33 Viruete, 2020: $\mathrm{n}^{\mathrm{o}} 165$.

34 Viruete, 2020: $\mathrm{n}^{\mathrm{o}} 206$.

35 Viruete, 2020: $\mathrm{n}^{\circ} 177$.

36 Viruete, 2020: $\mathrm{n}^{\circ} 262$.

37 Viruete, 2020: n⿳3 313

38 Lara, 1984. 
propiedades a personas dependientes: el servicio de acapto. ${ }^{39}$ En Santa Cilia de Panzano está documentado a partir del inicio del último cuarto del siglo XII, concretamente desde $1176 .{ }^{40}$ Existen tres cesiones de propiedad con este tributo: veinte sueldos jaqueses de cuatro dineros a Pedro de Yaso por tres campos y una viña en Panzano en el $1176 ;{ }^{41}$ cincuenta sueldos a Domingo Picador por las casas y un corral dentro del palacio del priorato en Panzano en $1178 ;{ }^{42}$ y ochenta sueldos a Sancho Blasch por la heredad de Coscullano en $1180 .{ }^{43}$ En el dominio de San Pedro el Viejo de Huesca también se impuso el tributo de acapto por conceder en feudo bienes del priorato. ${ }^{44}$

¿Cuándo se procede al pago de las rentas que han de hacer las personas que trabajan las propiedades del priorato de Santa Cilia de Panzano? Aquí también se observa disparidad de fechas, si bien solo se indica cuando la renta es censo en la localidad de Panzano. Las posesiones entregadas a Juan, capellán de Montearagón, en 1161, a Fortún de Navardún y su esposa Gason en 1166, y a Pedro de Yaso en 1176, tributaron el 22 de noviembre, día de Santa Cecilia, advocación a la que está consagrado el priorato. ${ }^{45}$ Por el contrario, Domingo Picador hubo de satisfacer su censo el día de San Miguel Arcángel, el 29 de septiembre, el conjunto de los vecinos de Panzano entregaron los censos debidos el día de San Nicolás, 24 de diciembre, y Poncio y sus hermanos en agosto, presumiblemente el quince, día de la Virgen. ${ }^{46}$ En el conjunto del dominio de San Pedro el Viejo de Huesca, incluyendo San Úrbez de Serrablo y la propia Santa Cilia, la mayoría de rentas se pagaron para la festividad de San Miguel Arcángel. ${ }^{47}$

¿En qué condiciones se entregaron en feudo las propiedades de Santa Cilia de Panzano? Partiendo de un análisis de conjunto, se establecen diversas condiciones, aunque no todas aparecen en cada uno de los documentos estudiados.

\footnotetext{
39 Rosa Fort señala 'entregar en feudo' como una de las acepciones de 'acaptar. (Fort, 1994: 227).

40 Viruete, 2020: $\mathrm{n}^{\circ} 206$.

41 Viruete, 2020: $\mathrm{n}^{\circ} 206$.

42 Viruete, 2020: $\mathrm{n}^{\circ} 217$.

43 Viruete, 2020: $\mathrm{n}^{\circ} 220$.

44 La primera mención a este tributo data del año 1165. Bernardo Ferrer y su mujer pagan ciento cuarenta sueldos jaqueses para obtener el usufructo de unas casas del priorato de San Pedro el Viejo en Huesca, las cuales había donado Miguel de Lizana. (Viruete, 2020: $\mathrm{n}^{\circ} 162$ ).

45 Viruete, 2020: $n^{\circ} 145,165$ y 206.

46 Viruete, 2020: no 217, 262 y 313.

47 Viruete, en prensa.
} 
En primer lugar, se estableció que el priorato podía cambiar cuando quisiera al usufructuario de un bien, entregándole otro. ${ }^{48}$ Una segunda condición de la que queda constancia es que los usufructuarios del bien podían donar, vender o empeñar el bien concedido a un tercero, siempre y cuando ese tercero pagase la carga establecida y no perteneciese al estamento militar o al religioso cuyos miembros solían gozar de exenciones fiscales. ${ }^{49}$

Otra de las condiciones observadas es el derecho de adquisición preferente del priorato para recuperar el dominio directo de un bien concedido. De la misma manera, el usufructuario, si deseaba donar, vender, permutar o empeñar el bien a un tercero, había de comunicarlo al priorato para, en el caso de considerarlo oportuno, éste pudiese ejercer su derecho. ${ }^{50}$ Finalmente, los usufructuarios de los bienes de Santa Cilia de Panzano, al menos en los casos que se especifican para el lugar de Panzano, estaban obligados a mantener la integridad del bien concedido. ${ }^{51}$

No tenemos constancia escrita de que se hubiesen puesto en explotación todas las propiedades del priorato. Ello puede deberse a dos circunstancias: que no se han conservado todos los documentos del priorato o estas se hacían de modo oral en un buen porcentaje. ${ }^{52}$

Una cuestión importante que reflejan los escasos documentos conservados del siglo XII del priorato de Santa Cilia de Panzano es la conflictividad surgida en el seno del señorío. Se constatan sendos casos en los lugares de Arraro y Morrano. Sancho Ramírez concedió a Saint-Pons-de-Thomières el diezmo de los habitantes del castro de Arraro. Sin embargo, estos intentaron no pagarlo, derivando la situación en un pleito que tardó en resolverse; casi tres décadas después, en el año 1133, Ramiro Sánchez, el futuro Ramiro II, estableció que los hombres de Arraro procedieran a pagar el citado tributo, decisión que los

48 Así sucede en abril de 1175, cuando Raimundo de Aura, prior entonces de Santa Cilia de Panzano, concede a Pedro de Aín las casas que tenía Íñigo de Laves en ese momento. A cambio, el priorato recupera de nuevo el dominio directo de las propiedades que hasta la fecha tenía del priorato Pedro de Aín: casas cerca de la iglesia de San Pedro de Panzano y dos viñas también en Panzano. (Viruete, 2020: $\mathrm{n}^{\circ} 200$ ).

49 Viruete, 2020: $\mathrm{n}^{\circ} 165$. El mantenimiento de la carga no se cita en este documento, pero es muy frecuente en los relacionados con San Pedro el Viejo de Huesca, priorato al que está sometido Santa Cilia de Panzano.

50 Viruete, 2020: $n^{\circ} 211$. También dentro de este caso hemos de interpretar la compra de unas casas en Santa Cilia de Panzano en febrero de 1142, cuando todo el término de este lugar es del priorato desde 1102. (Viruete, 2020: $\mathrm{n}^{\mathrm{o}} 103$ ).

51 Viruete, 2020: $\mathrm{n}^{\circ} 217$ y 220.

52 José María Lacarra ya señaló este hecho para la infeudación de honores entre el rey y la nobleza en el siglo XI, idea vuelta a reafirmar con posterioridad por Carlos Laliena. No creo que deba descartarse tampoco para el siglo XII. (Lacarra, 1968a: 485-528; Laliena, 1999b: 229-236). 
de Arraro acabaron acatando. ${ }^{53}$ El conflicto en Morrano se desarrolló algo más tarde, entre el reinado de Ramiro II y el inicio de la década de los años setenta. Estuvo protagonizado por un grupo familiar que trabajaba las propiedades del priorato en este lugar, antes de que éstas aumentaran con la donación de una casa hecha por Pedro de Labata. Frente a las quejas del priorato por no ingresar las rentas, los usufructuarios de las propiedades dejaron de pagar los tributos debidos alegando que tenían un documento del rey Ramiro II que les eximía de hacerlo. ${ }^{54}$ La casa madre de Saint-Pons-de-Thomières en Aragón, el priorato de San Pedro el Viejo de Huesca, intervino defendiendo sus derechos. Al final, en 1171 se produjo un acuerdo entre ambas partes: Fortí, capellán de San Pedro el Viejo, con la aprobación del prior Poncio, condonó al grupo familiar rebelde las rentas reclamadas. El acuerdo contemplaba que la aceptación de la dependencia de Santa Cilia de Panzano por parte del grupo campesino y el compromiso de pagar lo debido en concepto del usufructo de la heredad del priorato que trabajaban, dando las oportunas garantías mediante fiadores. Las rentas señoriales que debían abonar anualmente eran la novena de todos los frutos procedentes de la tierra y la novena de carne, esto es, de aquellos animales que criasen, que no quedan especificados en el documento..$^{55}$

Estas resistencias campesinas se contextualizan en el marco de la conflictividad que se produjo en Aragón durante el fin del siglo XI y a lo largo siglo XII, como bien ha estudiado Carlos Laliena. ${ }^{56}$ En el caso que nos ocupa, la solución de los conflictos entre el priorato de Santa Cilia de Panzano y sus dependientes parecen producirse de manera no violenta y sin salir del ámbito de las autoridades rectoras del priorato de San Pedro el Viejo o muy influyentes en el mismo: el rey Ramiro II, poco antes de secularizarse para acceder al trono, y el prior. ${ }^{57}$ No obstante, la lectura lineal de la documentación no permite avanzar más en esta cuestión. Se hace necesario un estudio más profundo del resto de la documentación de San Pedro el Viejo de Huesca y de San Úrbez

53 Viruete, 2020: $n^{\circ}$ 93. Dos años antes, el futuro Ramiro II llega a otro acuerdo sobre un conflicto con Raimundo Geraldo y los monjes de San Pedro el Viejo de Huesca. (Viruete, 2020: $\mathrm{n}^{\circ} 88$ ).

54 Quizás se pudieran referir al documento por el que Ramiro II concede a Calbet de Morrano y a sus hermanos la exención de tributos en su heredad de Morrano y en todas aquellas tierras que compraran o pusieran en cultivo. Viruete, 2020: $n^{\circ} 100$.

55 Viruete, 2020: $n^{\circ} 103$.

56 Carlos Laliena publicó en 2013 una obra de conjunto sobre la servidumbre en Aragón entre los siglos XI y XIII y en 2016 Guillermo Tomás estudió estas cuestiones en el territorio de la Ribagorza. (Laliena, 2013; Tomás, 2016).

57 Viruete, 2020: nº 93 y 103. 
de Serrablo - y su contextualización con el resto de Aragón — a fin de obtener un mejor conocimiento de estos episodios de rebeldía de los campesinos frente al priorato, al que debían satisfacer parte de la riqueza que generaban. Esto permitirá no solo comparar los regímenes de tenencia de la tierra entre San Pedro el Viejo y sus dos prioratos dependientes, sino también constatar si realmente existen diferentes grados de presión fiscal entre ellos.

\section{Conclusiones}

En el momento actual de nuestra investigación, el análisis de la documentación del priorato de Santa Cilia de Panzano permite confirmar varias de las hipótesis planteadas en este trabajo. En primer lugar, el priorato de Santa Cilia de Panzano se fundó entre 1099 y 1101 y dependió del priorato de San Pedro el Viejo de Huesca, que a su vez fue sufragáneo de la abadía francesa de SaintPons-de-Thomières, ubicada en el departamento francés de Hérault, con capital en Montpellier.

En segundo lugar, se comprueba que el dominio del priorato de Santa Cilia de Panzano fue pequeño y compacto. Localizado en el noroeste de la comarca de La Hoya de Huesca, en el somontano al sur de la Sierra de Guara, sus tierras se hayan surcadas por los ríos Calcón y Formiga, afluentes del Alcanadre en su curso alto.

En tercer lugar, al margen de las rentas eclesiásticas, la documentación no trasluce igualdad en la condición social de todas las personas vinculadas con Santa Cilia de Panzano: los datos permiten afirmar que soportaron una mayor dureza quienes trabajaron las heredades de Morrano, Coscullano y Blecua. Por el contrario, los usufructuarios de su patrimonio en Panzano únicamente pagaron censo como renta feudal, bien en metálico, bien en especie.

Por último, el priorato de Santa Cilia de Panzano introdujo un nuevo tributo - el acapto - en el último cuarto del siglo XII que abonaron quienes recibieron en usufructo una de sus propiedades. Sin embargo, resulta difícil valorar si ello significó un endurecimiento de las condiciones de vida de los usufructuarios que trabajaron su patrimonio, porque desconocemos con precisión la coyuntura económica. La escasa documentación conservada impide plantear una tesis sólida al respecto. No obstante, creemos que la imposición del acapto pudo constituir un intento del priorato de no empobrecer sus ingresos habiendo un crecimiento económico y una rebaja en algunos censos. 


\section{Referencias bibliográficas}

Arilla NaVArro, Silvia y José Ángel Asensio ESTEBAN (2017) «La Magdalena de Panzano (Casbas de Huesca), una torre defensiva andalusí en el distrito de hisn Labata. El poblamiento campesino del interfluvio Calcón-Formiga entre los siglos X y XII», Bolskan, 26: 65-94.

BALAGUER SÁNCHEZ, Federico (1946a) «Notas documentales sobre mozárabes oscenses», Estudios de Edad Media de la Corona de Aragón, 2: 397-416.

BALAguer SÁNCHEZ, Federico (1946b) Un monasterio medieval, San Pedro el Viejo. Huesca, Museo Arqueológico de Huesca.

BALDELLOU MARTínEZ, Vicente (2006) «Los primeros asentamientos humanos.» En Adolfo Castán Sarasa, coord., Comarca La Hoya de Huesca. Zaragoza, Gobierno de Aragón: 59-74.

Buesa Conde, Domingo José (1978) Sancho Ramírez. Zaragoza, Guara Editorial.

BuESA Conde, Domingo José (1996) Sancho Ramírez, rey de aragoneses y de pamploneses. Zaragoza, Ibercaja.

CANELlAS LÓPEZ, Ángel (1943) «El monasterio de San Úrbez de Serrablo», Universidad, 20: 3-34.

CASTÁN EsCRIBANO, Sescún (2006) «Flora y vegetación.» En Adolfo Castán Sarasa, coord., Comarca La Hoya de Huesca. Zaragoza, Gobierno de Aragón: 33-56.

CONTE CAZCARro, Ánchel (2010) «La encomienda templaria de Huesca en el siglo XII.» En Josep Maria Sans i Travé y Josep Serrano Daura (coords.), Actes de les Jornades Internacionals d'Estudi sobre els Orígens i l'Expansió de l'Orde del Temple a la Corona d'Aragó (1120-1200). Tarragona, Diputación Provincial de Tarragona: 285-318.

CUCHI OTERINO, José Antonio (2006a) «El relieve, el clima y la red hidrográfica.» En Adolfo Castán Sarasa (coord.), Comarca La Hoya de Huesca. Zaragoza, Gobierno de Aragón: 21-26.

CUCHI OTERINO, José Antonio (2006b) «Geología y geomorfología.» En Adolfo Castán Sarasa (coord.), Comarca La Hoya de Huesca. Zaragoza, Gobierno de Aragón: 27-32.

DefourneauX, Michel (1949) Les Français en Espagne aux XI et XII siècles. Paris, Presses universitaires.

Del ARCO Y GARAY, Ricardo (1963) «El monasterio de Montearagón», Argensola, 53-54: $1-50$.

DURÁn GUDIOL Antonio (1962) La Iglesia en Aragón durante los reinados de Sancho Ramirez y Pedro I, 1062?-1104. Roma, Instituto Español de Historia Eclesiástica.

FORT CANELLAS, Rosa (1994) Léxico romance en documentos medievales aragoneses. (Siglos XI y XII). Zaragoza, Gobierno de Aragón.

GARCía GARCíA, Francisco de Asís (2018) Las portadas de la catedral de Jaca. Huesca, Instituto de Estudios Altoaragoneses. 
Gargallo Moya, Antonio, María Teresa Iranzo MuÑío y María José SÁnCHEZ USÓN (1981) «Aportación al estudio del dominio del Temple en Huesca», Aragón en la Edad Media, 4: 7-56.

GIUNTA, Alexandre (2012) «'Illos seniores de Sancto Iacopo de Rosta': l'implantation de l'abbaye de Sauve-Majeure en Aragon (XI'-XII ${ }^{\mathrm{e}}$ siècles)», Aragón en la Edad Media, 23: 123-142.

GIUNTA, Alexandre (2017) Les francos dans la vallée de l'Ebre (XI'-XII' siècles). Toulouse, Presses universitaires du Mirail.

KHER, Paul (1945) «Cómo y cuándo se hizo Aragón feudatario de la Santa Sede», Estudios de Edad Media de la Corona de Aragón, 1: 285-326.

KHER, Paul (1946) «El Papado y los Reinos de Navarra y Aragón hasta mediados del siglo XII», Estudios de Edad Media de la Corona de Aragón, 2: 74-185.

LACARRA Y DE Miguel, José María (1968a) «'Honores' et 'tenencias' en Aragon (XI siècle)», Annales du Midi, 80: 485-528.

LACARRA Y DE MiguEL, José María (1968b) «Los franceses en la reconquista y repoblación del Valle del Ebro en tiempos de Alfonso El Batallador», Hispania, extra 2: $65-80$.

LACARRA Y DE Miguel, José María (1977) Alfonso I de Aragón. Zaragoza, Guara Editorial.

LALIENA CORBERA, Carlos (1996) La formación del Estado feudal. Aragón y Navarra en la época de Pedro I. Huesca, Instituto de Estudios Altoaragoneses.

LALIENA CorberA, Carlos (1999a) «Un mundo ancestral. Campesinos del Prepirineo aragonés en el siglo XI», Aragón en la Edad Media, 14-15: 831-846.

LALIENA CORBERA, Carlos (1999b) «'Illum expugnabo atque inimicus ero.' Acuerdos feudales en la formación del Estado aragonés (siglo XI)» En Hélène Débax (éd.), Les sociétés médiévales à l'âge féodal (Espagne, Italie et sud de la France Xe-XIII ${ }^{e}$ siécles) Hommage à Pierre Bonnassie. Toulouse, Presses Universitaires du Mirail: 229-254.

LALIENA CORBERA, Carlos (2000) «'Larga stipendia et optima praedia': les nobles francos en Aragon au service d'Alphonse le Batailleur», Annales du Midi, 112: 149-169.

Laliena Corbera, Carlos (2013) Siervos medievales de Aragón y Navarra en los siglos XI-XIII. Zaragoza, Prensas de la Universidad de Zaragoza.

LARA IZQUIERDO, Pablo (1984) Sistema aragonés de pesos y medidas. La metrología histórica aragonesa y sus relaciones con la castellana. Zaragoza, Guara Editorial. MARTín DuQUE, Ángel Juan. (1957) «El dominio del monasterio de San Victorián de Sobrarbe en Huesca durante el siglo XII», Argensola, 30: 93-109.

Rodrigo Estevan, María Luz y María del Mar Agudo RoMEO (en prensa) «Cristianos mozárabes, musulmanes y judíos en la documentación de Alfonso I de Aragón (1104-1134)», en Pierre Louis Giannerini, éd., Échanges et confrontations entre chrétiens et musulmans à l'époque du vicomte de Bearn Gaston IV et du roi 
d'Aragon Alphonse I'r (1090-1134). III Transpyrenalia (Oloron-Sainte Marie, déc. 2018).

SÉNAC, Philippe (2000) La frontière et les hommes (VIII -XII siècles). Le peuplement musulman au nord de l'Ebre et les debuts de la reconquête aragonaise. Paris, Maisonneuve \& Larose.

TOMÁs FACI, Guillermo (2016) Montañas, comunidades y cambio social en el Pirineo medieval. Ribagorza en los siglos X-XIV. Toulouse, Presses Universitaires du Mirail y Prensas de la Universidad de Zaragoza.

UTRILLA UTRILlA, Juan Fernando (1984) «El dominio de la catedral de Huesca en el siglo XII: notas sobre su formación y localización», Aragón en la Edad Media, 6: $19-46$.

VIRUETE ERDOZÁIn, Roberto (2008) Aragón en la época de Ramiro I. Zaragoza, Universidad Disponible en red: https://zaguan.unizar.es/record/3230/files/TESIS-2009-054.pdf

Viruete ERdozÁIn, Roberto (2020) Documentos de San Pedro el Viejo de Huesca (siglos $X$-XII). Huesca, Instituto de Estudios Altoaragoneses.

VIRUETE ERDOZÁIN, Roberto (en prensa) «La documentación de San Pedro el Viejo en el Ayuntamiento de Huesca (siglos X-XII): posibilidades de explotación histórica.» En Pierre Louis Giannerini, éd., Échanges et confrontations entre chrétiens et musulmans à l'époque du vicomte de Bearn Gaston IV et du roi d'Aragon Alphonse Ir (1090-1134). III Transpyrenalia (Oloron-Sainte Marie, déc. 2018). 
